\title{
Skeletal metastases: what is the future role for nuclear medicine?
}

\author{
Gary J. R. Cook
}

Published online: 13 August 2009

(C) Springer-Verlag 2009

\begin{abstract}
Although planar bone scintigraphy with ${ }^{99 \mathrm{~m}}$ Tc-labelled bisphosphonates has been the mainstay for imaging skeletal metastases for nearly four decades, it has been limited by poor specificity and has been losing ground to the improving anatomical imaging modalities such as multislice CT and newly developing whole body MRI imaging techniques $[1,2]$. The addition of SPECT to planar bone scintigraphy improves sensitivity and specificity to a degree [3] but has not been able to negate the need for anatomical imaging correlation, leading to extra imaging procedures for the patient and a subsequent delay in clinical management decisions. The advent of hybrid SPECT/CT and PET/ CT would therefore seem to be a natural progression towards optimal assessment of skeletal metastases, incorporating both functional information for sensitivity and anatomical information for specificity in a single comprehensive test. Hybrid MRI scanners are also in development and may have more to offer in view of MRI's particular sensitivity for bone-marrow-based disease.

Hybrid SPECT/CT with diagnostic quality CT has partly been driven by the success of PET/CT, and as a relatively recently available modality, the evidence for incremental benefit in imaging bone metastases is only just starting to accrue [4-7].
\end{abstract}

This Editorial Commentary refers to the article doi:10.1007/s00259009-1181-2

\section{G. J. R. Cook $(\bowtie)$}

Department of Nuclear Medicine and PET,

The Royal Marsden NHS Foundation Trust,

Downs Road, Sutton, Surrey SM2 5PT, UK

e-mail: gcook@icr.ac.uk
Utsunomiya et al. have shown an incremental benefit of fused SPECT/CT compared to separate SPECT and CT images or planar and SPECT images [4]. Fused images allowed greater diagnostic certainty with fewer equivocal lesions, better interobserver agreement and greater overall diagnostic accuracy in diagnosing benign and malignant bone lesions as measured by ROC analysis. Fused SPECT/ $\mathrm{CT}$ allowed indeterminate lesions to be classified as benign or malignant in 17/82 lesions for one observer and 8/82 for another observer. The correct classification of benign lesions was more frequent for both observers, thus predominantly improving specificity.

In a similar retrospective study of bone SPECT/CT, Romer et al. analysed 52 indeterminate skeletal lesions on SPECT in 44 patients being staged for malignancy [5]. Approximately two-thirds of lesions were classified as benign and in only four lesions was it not possible to classify them as benign or malignant with SPECT/CT.

As bone scintigraphy remains in frequent use and is readily available for staging many cancers, it seems likely that it will continue to have a significant and enhanced clinical role in its new form of SPECT/CT as combined SPECT/CT scanners become more widely available.

However, interest in evaluating skeletal metastases with $\mathrm{PET} / \mathrm{CT}$ techniques is increasing. It is possible to take advantage of two aspects of metabolic changes associated with bone metastases with two readily available PET tracers, namely ${ }^{18} \mathrm{~F}$-fluoride and ${ }^{18} \mathrm{FDG}$. With a similar mechanism of uptake to ${ }^{99 \mathrm{~m}} \mathrm{Tc}$-labelled bisphosphonates, ${ }^{18} \mathrm{~F}$-fluoride has been available as a bone-specific tracer for many years and the properties of ${ }^{18} \mathrm{FDG}$ as a tumourspecific agent are well recognised. 
The skeletal clearance of ${ }^{18} \mathrm{~F}$-fluoride ion is similar to ${ }^{99 \mathrm{~m}} \mathrm{Tc}$-labelled bisphosphonates in that it reflects a combination of local blood flow and osteoblastic activity [8]. The pharmacokinetics differ from ${ }^{99 \mathrm{~m}} \mathrm{Tc}$-labelled bisphosphonates in that there is little protein binding, and unlike bisphosphonates, renal tubular reabsorption occurs. Evidence suggests that ${ }^{18} \mathrm{~F}$-fluoride undergoes high first-pass extraction in bone, approaching $100 \%$ at physiological blood flow rates, and similar to ${ }^{99 \mathrm{~m}} \mathrm{Tc}-$ labelled bisphosphonates, there is chemisorption into bone crystals with the formation of fluorapatite. This process occurs preferentially at sites of actively mineralising bone $[9,10]$.

In the era before hybrid PET/CT, a number of comparisons of ${ }^{18} \mathrm{~F}$-fluoride PET and planar $+/-$ SPECT bone scintigraphy were performed in the diagnosis of skeletal metastases. These generally showed an improved diagnostic accuracy for the PET method, particularly when compared to planar scintigraphy alone [11-14]

In a study of 34 patients with breast cancer, ${ }^{18} \mathrm{~F}$-fluoride PET detected 64 metastases in 17 patients compared to planar bone scintigraphy, which only detected 29 metastases in 11 patients. ${ }^{18} \mathrm{~F}$-fluoride PET led to a change in management in $12 \%$ of patients overall [11]. The greatest incremental benefit of ${ }^{18} \mathrm{~F}$-fluoride PET is in the spine and pelvis compared to the skull, thorax and extremities [12].

However, this raised the question of whether the improved spatial resolution of PET and inherent tomography were responsible for the greater accuracy or whether this was due to a difference in the pharmacokinetics and bone uptake mechanisms between the types of tracer. To some extent an answer to this question was suggested in a subsequent analysis by Schirrmeister and colleagues in patients with lung cancer [13]. Of 53 patients with lung cancer, 12 had bone metastases for which there were six false-negatives with planar scintigraphy, one false-negative with planar scintigraphy augmented with SPECT and no false-negatives with ${ }^{18} \mathrm{~F}$-fluoride PET. Six patients had management altered as a result of ${ }^{18} \mathrm{~F}$-fluoride PET and five due to SPECT. The difference between PET and SPECT as measured by the area under the ROC curves was not statistically significant. These findings suggest that the differences between bone scintigraphy and ${ }^{18} \mathrm{~F}$-fluoride PET were mainly technical rather than due to mechanistic differences in the tracers. The same group took this analysis further in a group of 103 patients with lung cancer and on this occasion showed a statistically significant increase in the area under the ROC curve with ${ }^{18} \mathrm{~F}$-fluoride PET compared to SPECT and planar scintigraphy but it was noted that this was at higher incremental costs [14].

Unsurprisingly, when combined with $\mathrm{CT}$, as hybrid ${ }^{18} \mathrm{~F}$ fluoride PET/CT, diagnostic accuracy is improved when compared to PET alone $[15,16]$. The anatomic data provided by the low-dose CT component allowed better discrimination of benign and malignant lesions and usually obviated the need for a subsequent full-dose diagnostic CT in a group of 44 patients with various primary cancers [15]. Incremental value of ${ }^{18} \mathrm{~F}$-fluoride PET/CT was found in a further study of patients with prostate cancer when compared to planar bone scans, single and multi-field of view SPECT and ${ }^{18} \mathrm{~F}$-fluoride PET without CT [16].

Whilst many of the reported studies are either retrospective or involve only a limited number of patients, a randomised, prospective, multicentre study of over 500 patients with breast, prostate and lung cancers is underway in the United States comparing ${ }^{99 \mathrm{~m}} \mathrm{Tc}$ MDP planar bone scintigraphy with ${ }^{18} \mathrm{~F}$-fluoride PET/CT and the results are awaited with interest [17].

In the detection of skeletal metastases, ${ }^{18} \mathrm{FDG}$ is thought to act as a tumour-specific tracer and therefore has the potential advantage of being able to detect small bone marrow metastases before an osteoblastic reaction has occurred (in contrast to bone-specific tracers) or metastases that are predominantly osteolytic in nature with little or no osteoblastic reaction. However, ${ }^{18}$ FDG PET may not be as sensitive as MRI in detecting small bone marrow lesions in some tumour types [18].

Much of the literature describing PET and skeletal metastases compares bone scintigraphy with ${ }^{18} \mathrm{FDG}$ PET in patients with breast cancer [19-21]. The majority of studies indicate that ${ }^{18} \mathrm{FDG}$ PET is more accurate, although some show this is predominantly due to improved specificity rather than sensitivity $[19,20]$. It would appear that the sensitivity for lytic metastases is better with ${ }^{18} \mathrm{FDG}$ PET but that osteoblastic metastases are less ${ }^{18} \mathrm{FDG}$-avid with resultant poor sensitivity compared to bone scintigraphy [21-28]. Although there seems little doubt that lytic and sclerotic metastases behave differently with regards to ${ }^{18} \mathrm{FDG}$ uptake and that osteoblastic breast cancer lesions may be associated with a better prognosis [22], prior treatment probably influences this relationship [25]. Other tumours where ${ }^{18} \mathrm{FDG}$ PET or PET/CT have shown superior diagnostic accuracy compared to bone scintigraphy include lung cancer [29, 30], thyroid cancer [31], nasopharyngeal carcinoma [32] and oesophageal carcinoma [33]. However, one study found no apparent advantage of ${ }^{18} \mathrm{FDG}$ PET over bone scintigraphy in a variety of tumour types [34] and another found bone scintigraphy with SPECT more sensitive in breast cancer due to the poor sensitivity of ${ }^{18}$ FDG PET for osteoblastic lesions [28].

There is as yet little data available to determine the value of combined ${ }^{18} \mathrm{FDG}$ PET/CT compared to ${ }^{18} \mathrm{FDG}$ PET alone in bone metastases but at least one study suggests a complementary role for the PET and CT components of the examination by finding a much higher positive predictive 
value when PET and CT findings are concordant (98\%) compared to PET positive/CT negative discordant cases (PPV $=61 \%$ ) and PET negative / CT positive cases (PPV $=$ 17\%) [35]. A further study showed an improved specificity in the spine of patients with varied tumours when using ${ }^{18}$ FDG PET/CT compared to ${ }^{18}$ FDG PET alone [36].

However, many cancers are now routinely staged with ${ }^{18} \mathrm{FDG}$ PET/CT and the pertinent question is whether this method is sufficiently accurate in evaluating skeletal disease such that bone-specific methods, including bone scintigraphy (+/- SPECT and SPECT/CT) or ${ }^{18} \mathrm{~F}$-fluoride PET (or PET/CT), are superfluous.

In non-small-cell lung cancer staging it would appear that routine skeletal assessment with bone scintigraphy in symptomatic and asymptomatic patients can help avoid unnecessary surgery [37]. However, it has been shown that not only bone-specific PET imaging with ${ }^{18} \mathrm{~F}$-fluoride [14] but tumour specific imaging with ${ }^{18} \mathrm{FDG}$, are more accurate than bone scintigraphy in patients with lung cancer [29, 30]. As potentially curable NSCLC is now almost routinely staged with ${ }^{18} \mathrm{FDG} \mathrm{PET} / \mathrm{CT}$, the obvious question is whether bone-specific imaging, with SPECT, ${ }^{18} \mathrm{~F}$-fluoride PET or hybrid methods with $\mathrm{CT}$, are required at all.

In this issue of the journal, Kruger and colleagues present some interesting data comparing bone scintigraphy with SPECT of the axial skeleton, ${ }^{18} \mathrm{~F}$-fluoride PET and ${ }^{18}$ FDG PET/CT in patients with a new diagnosis of NSCLC [38]. Despite some limitations in retrospective design, individual patients not having all three tests, the use of ${ }^{18} \mathrm{~F}$-fluoride PET rather than ${ }^{18} \mathrm{~F}$-fluoride PET/CT and ${ }^{99 \mathrm{~m}} \mathrm{Tc}$ MDP SPECT rather than SPECT/CT, there is supportive evidence that ${ }^{18} \mathrm{FDG} \mathrm{PET} / \mathrm{CT}$ could at least replace bone scintigraphy in this group of patients.

Overall, ${ }^{18} \mathrm{FDG}$ PET/CT was found to be more sensitive than ${ }^{18} \mathrm{~F}$-fluoride PET but in spite of all the metastases being lytic in nature, there were four patients who had metastases identified with ${ }^{18} \mathrm{~F}$-fluoride PET but not with ${ }^{18} \mathrm{FDG}$ PET/CT. Although the number of patients who were ${ }^{18} \mathrm{~F}$-fluoride-positive but ${ }^{18} \mathrm{FDG}$-negative is small and we do not know if these corresponded to a particular histological subtype, it would seem too early to say that full nodal, visceral and skeletal staging of lung cancer can be performed by ${ }^{18} \mathrm{FDG}$ PET/CT alone. It seems possible that additional ${ }^{18} \mathrm{~F}$-fluoride PET or PET/CT might be able to help avoid futile curative therapy regimes but clearly a prospective trial of state-of-the-art imaging with ${ }^{99 \mathrm{~m}} \mathrm{Tc}-$ MDP SPECT/CT, ${ }^{18}$ F-fluoride PET/CT and ${ }^{18} \mathrm{FDG}$ PET/CT is required to clarify remaining questions and to guide us on the optimal way to assess the skeleton for metastases. It seems likely that nuclear medicine will continue to provide a significant contribution towards evaluation of skeletal metastases, almost certainly with hybrid imaging.

\section{References}

1. Sohaib SA, Cook G, Allen SD, Hughes M, Eisen T, Gore M. Comparison of whole-body MRI and bone scintigraphy in the detection of bone metastases in renal cancer. $\mathrm{Br} \mathrm{J}$ Radiol. 2009;82:632-9.

2. Kumar J, Seith A, Kumar A, et al. Whole-body MR imaging with the use of parallel imaging for detection of skeletal metastases in pediatric patients with small-cell neoplasms: comparison with skeletal scintigraphy and FDG PET/CT. Pediatr Radiol. 2008;38:953-62.

3. Savelli G, Maffioli L, Maccauro M, et al. Bone scintigraphy and the added value of SPECT (single photon emission tomography) in detecting skeletal lesions. Q J Nucl Med. 2001;45:27-37.

4. Utsunomiya D, Shiraishi S, Imuta $M$, et al. Added value of SPECT/CT fusion in assessing suspected bone metastasis: comparison with scintigraphy alone and nonfused scintigraphy and CT. Radiology. 2006;238:264-71.

5. Romer W, Nomayr A, Uder M, et al. SPECT-guided CT for evaluating foci of increased bone metabolism classified as indeterminate on SPECT in cancer patients. J Nucl Med. 2006;47:1102-6.

6. Horger M, Eschmann SM, Pfannenberg C, et al. Evaluation of combined transmission and emission tomography for classification of skeletal lesions. AJR Am J Roentgenol. 2004;183:655-61.

7. Buck AK, Nekolla S, Ziegler S, et al. SPECT/CT. J Nucl Med. 2008;49:1305-19.

8. Blake GM, Park-Holohan SJ, Cook GJR, Fogelman I. Quantitative studies of bone with the use of ${ }^{18} \mathrm{~F}$-fluoride and ${ }^{99 \mathrm{~m}} \mathrm{Tc}-\mathrm{MDP}$. Semin Nucl Med. 2001;31:28-49.

9. Bang S, Baud CA. Topographical distribution of fluoride in iliac bone of a fluoride-treated osteoporotic patient. J Bone Miner Res. 1990;5:S87-9.

10. Einhorn TA, Vigorita VJ, Aairon A. Localisation of technetium$99 \mathrm{~m}$ methylene diphsophonate in bone using microautoradiography. J Orthop Res. 1986;4:180-7.

11. Schirrmeister H, Guhlmann A, Kotzerke J, et al. Early detection and accurate description of extent of metastatic bone disease in breast cancer with fluoride ion and PET. J Clin Oncol. 1999;17:2381-9.

12. Schirrmeister H, Guhlmann A, Elsner K, et al. Sensitivity in detecting osseous lesions depends on anatomic localization: planar bone scintigraphy versus ${ }^{18} \mathrm{~F}$ PET. J Nucl Med. 1999;40:1623-9.

13. Schirrmeister H, Glatting G, Hetzel J, et al. ive evaluation of the clinical value of planar bone scans, SPECT, and ${ }^{18} \mathrm{~F}$-labeled NaF PET in newly diagnosed lung cancer. J Nucl Med. 2001;42:1800-4.

14. Hetzel M, Arslandemir C, König HH, et al. F-18 NaF PET for detection of bone metastases in lung cancer: accuracy, costeffectiveness, and impact on patient management. J Bone Miner Res. 2003;18:2206-14.

15. Even-Sapir E, Metser U, Flusser G, et al. Assessment of malignant skeletal disease: initial experience with ${ }^{18} \mathrm{~F}$-fluoride PET/CT and comparison between ${ }^{18} \mathrm{~F}$-fluoride PET and ${ }^{18} \mathrm{~F}$-fluoride PET/CT. J Nucl Med. 2004;45:272-8.

16. Even-Sapir E, Metser U, Mishani E, Lievshitz G, Lerman H, Leibovitch I. The detection of bone metastases in patients with high-risk prostate cancer: ${ }^{99 \mathrm{~m}} \mathrm{Tc}-\mathrm{MDP}$ planar bone scintigraphy, single- and multi-field-of-view SPECT, ${ }^{18} \mathrm{~F}$-fluoride PET, and ${ }^{18} \mathrm{~F}$ fluoride PET/CT. J Nucl Med. 2006;47:287-97.

17. http://www.ami-imaging.org/index.php?option=com_content\& task $=$ view\&id $=173 \&$ Itemid $=119$

18. Ghanem NA, Pache G, Lohrmann C, et al. MRI and (18)FDGPET in the assessment of bone marrow infiltration of the spine in cancer patients. Eur Spine J. 2007;16:1907-12. 
19. Ohta M, Tokuda Y, Suzuki Y, et al. Whole body PET for the evaluation of bony metastases in patients with breast cancer; comparison with ${ }^{99 \mathrm{~m}} \mathrm{Tc}-\mathrm{MDP}$ bone scintigraphy. Nucl Med Commun. 2001;22:875-9.

20. Yang SN, Liang JA, Lin FJ, Kao CH, Liu CC, Lee CC. Comparing whole body (18)F-2-deoxyglucose PET and Tc-99m MDP bone scan to detect bone metastases in patients with breast cancer. J Cancer Res Clin Oncol. 2002;128:325-8.

21. Abe K, Sasaki M, Kuwabara Y, et al. Comparison of ${ }^{18}$ FDG-PET with ${ }^{99 \mathrm{~m}} \mathrm{Tc}-\mathrm{HMDP}$ scintigraphy for the detection of bone metastases in patients with breast cancer. Ann Nucl Med. 2005;19:573-9.

22. Cook GJR, Houston S, Rubens R, Maisey MN, Fogelman I. Detection of bone metastases in breast cancer by 18 FDG PET: differing metabolic activity in osteoblastic and osteolytic lesions. J Clin Oncol. 1998;16:3375-9.

23. Hugye V, Garcia C, Vanderstappen A, Alexiou J, Gil T, Flamen P. Progressive osteoblastic bone metastases in breast cancer negative on FDG-PET. Clin Nucl Med. 2009;34:417-20.

24. Hur J, Yoon CS, Ryu YH, Yun MJ, Suh JS. Accuracy of FDG PET for diagnosis of single bone metastasis: comparison with bone scintigraphy. J Comput Assist Tomogr. 2007;31:812-9.

25. Israel $\mathrm{O}$, Goldberg $\mathrm{A}$, Nachtigal $\mathrm{A}$, et al. FDG-PET and $\mathrm{CT}$ patterns of bone metastases and their relationship to previously administered anti-cancer therapy. Eur J Nucl Med Mol Imaging. 2006;33:1280-4.

26. Nakai T, Okuyama C, Kubota T, et al. Pitfalls of FDG-PET for the diagnosis of osteoblastic bone metastases in patients with breast cancer. Eur J Nucl Med Mol Imaging. 2005;32:1253-8.

27. Gallowitsch HJ, Kresnik E, Gasser J, et al. F-18 FDG PET in the diagnosis of tumor recurrence and metastases in the follow up of patients with breast carcinoma: a comparison to conventional imaging. Invest Radiol. 2003;38:250-6.

28. Uematsu T, Yuen S, Yukisawa S, et al. Comparison of FDG PET and SPECT for detection of bone metastases in breast cancer. AJR Am J Roentgenol. 2005;184:1266-73.
29. Bury T, Baretto A, Daenen F, Barthelemy N, Ghaye B, Rigo P. F18 FDG PET for the detection of bone metastases in patients with non-small cell lung cancer. Eur J Nucl Med. 1998;25:1244-7.

30. Song JW, Oh YM, Shim TS, et al. Efficacy comparison between (18)F-FDG PET/CT and bone scintigraphy in detecting bony metastases of non-small cell lung cancer. Lung Cancer. 2009; doi:10.1016/j.lungcan.2008.12.004.

31. Ito S, Kato K, Ikeda M, et al. Comparison of ${ }^{18} \mathrm{~F}$-FDG PET and bone scintigraphy in detection of bone metastases of thyroid cancer. J Nucl Med. 2007;48:889-95.

32. Liu FY, Chang JT, Wang HM, et al. [18F]FDG PET is more sensitive than skeletal scintigraphy for detecting bone metastasis in endemic nasopharyngeal carcinoma at initial staging. J Clin Oncol. 2006;24:599-604.

33. Kato H, Miyazaki T, Nakajima M, et al. Comparison between whole body PET and bone scintigraphy in evaluating bony metastases of esophageal carcinoma. Anticancer Res. 2005;25: 4439-44.

34. Fujimoto R, Higashi T, Nakamoto Y, et al. Diagnostic accuracy of bone metastases detection in cancer patients: comparison between bone scintigraphy and whole-body FDG-PET. Ann Nucl Med. 2006;20:399-408.

35. Taira AV, Herfkens RJ, Gambhir SS, Quon A. Detection of bone metastases: assessment of integrated FDG PET/CT imaging. Radiology. 2007;243:204-11.

36. Metser U, Lerman H, Blank A, Lievshitz G, Bokstein F, EvenSapir E. Malignant involvement of the spine: assessment by ${ }^{18} \mathrm{~F}-$ FDG PET/CT. J Nucl Med. 2004;45:279-84.

37. Schirrmeister H, Arslandemir C, Glatting G, et al. Omission of bone scanning according to staging guidelines leads to futile therapy in non-small cell lung cancer. Eur J Nucl Med Mol Imaging. 2004;31:964-8.

38. Krüger S, Buck AK, Mottaghy FM, et al. Detection of bone metastases in patients with lung cancer: ${ }^{99 \mathrm{~m}} \mathrm{Tc}-\mathrm{MDP}$ planar bone scintigraphy, ${ }^{18}$ F-Fluoride PET or ${ }^{18}$ F-FDG PET-CT. Eur J Nucl Med Mol Imaging. 2009; doi:10.1007/s00259-009-1181-2. 